\title{
Research on the University Flipped Classroom Based on the Network Platform
}

\author{
Yangqing Zhu \\ Electronic Information Engineering School, Foshan University, China. \\ zhuyangqing_830516@163.com
}

\begin{abstract}
Keywords: Flipped Classroom, Network Platform, Making Micro Video Lesson, Improving Education Quality.
\end{abstract}

\begin{abstract}
Flipped classroom, as a model of deep integration of information technology and learning theory, has become a hot topic in the reform of higher education in recent years. Flipped classroom is an advanced teaching model \& learning before teaching, which is from passive learning to active learning. The flipped classroom is based on the theory of mastery learning, constructivism, cognitive load, effective teaching and so on. The flipped classroom effectively improved the students' learning initiative and learning effect. The flipped classroom provided an effective way to the reform of university curriculum and improving university educational quality.
\end{abstract}

\section{Introduction}

The flipped classroom originated from classroom teaching experiment of university. In early 1990s, Harvard University Mazur Eric professor has been explored this teaching model [1]. In 1998, Barbara $\&$ Anderson publicized the role of the flipped classroom method in a book of naming "effective guidance" [2]. But this concept was first put forward by J. Wes-ley Baker in the Cedarville University in the 11th international conference on university teaching in the 2000 year, he published a paper of "The classroom flip: using web course management tools to become the guide by the side". In 2007, Colorado State Forest Park high school two chemistry teachers Jonathan Bergmann and Aaron Sams first carried out the experiment in the teaching of senior high school, they made the students at home to watch the pre-recorded short video to achieve new knowledge learning, in the classroom more carried out interaction in answering questions, discussion and research. At the same time, Salman Khan freely open thousands of micro video in YouTube, set up the Khan Academy, directly promoted the teaching mode pop up quickly in the United States [3]. Since 2010, Chinese educators have begun to practice and theoretical research on flipped classroom. In this paper, analyzed the flipped classroom connotation and significance, and the role of the teacher in the flipped classroom, and carried out the practical exploration of the flipped classroom teaching based on the network teaching platform.

\section{The Connotation of Flipped Classroom}

The flipped classroom is a flip of the traditional teaching, students first contact the course future learn new materials, such as reading literature or watch video lectures, and then in the classroom time through problem solving, discussion or debate strategy to achieve knowledge internalization. Flipped classroom is actually a kind mode of learning before teaching, it is not only the change of time and space, flow and structure, but also a kind of paradigm transformation [4]. The role and expectations of teachers and students have changed, the students become the master of learning, and the teacher turned to the guidance of the students.

\section{The Educational Significance of Flipped Classroom}

Provide Personalized Guidance for Students' Learning. Flipped classroom provides students with personalized learning space and learning methods, students have the opportunity to master the progress and depth of learning. Flipped classroom was a more humane learning strategies, it shifted the traditional classroom direct teaching content to the outside of the class, teaching knowledge 
through video, and the saved time were used in the learning needs of different students. Teachers can carry out one to one guidance for students in the classroom, they have the opportunity to talk with each student and assess the student's learning situation, effectively improve the student's learning effect. At the same time, students will feel the importance of learning and find a sense of being. Flipped classroom breaks the limitation of traditional teaching, so that students have more experience opportunities to promote knowledge internalization, improve learning methods and learning ability, which is conducive to the long-term development of students. In the flipped classroom teaching mode, the classroom is used to achieve the students' individual learning, students show their learning achievements through personalized project [5].

Enhance the Student's Participation and Teamwork. In the flipped classroom teaching mode, the students' knowledge internalization place is the classroom. The teaching activities of teachers are composed of concept exploration and experiment, and the students' learning activities are composed of meaning construction, demonstration and application. Teachers can help students to achieve the internalization of knowledge through the game, discussion, experiment and other diverse activities, so that students can develop their subject awareness, problem awareness and exploring ability. Whether students watch the video before class, or collaborative activities in class, students get constructing knowledge ability, become the master of learning, show and enhance the subject consciousness. This cooperative learning between teachers and students has inspired the students' learning motivation and improved the degree of classroom participation. Students can interact with peers and teachers through social media to explore and solve the problems encountered in the course study. In the classroom, teacher arranges the group cooperation study according to the students' characteristics, each member of the group completes the study task through participation, exchange and cooperation [6].

Enhance Teacher's Educational Philosophy and Professional Ability. Teacher's educational philosophy and professional ability are the key to the teaching reform. Take students as the present must become teachers' educational philosophy. In the flipped classroom teaching mode, teachers should have certain teaching resources integration ability, production ability of teaching video, a high level of classroom organization ability and classroom management skills [7].

\section{The Role of Teachers in the Flipped Classroom Teaching}

Design Guidance Scheme. Guidance scheme is to instruct students to complete the task of learning and enhance the learning ability. In the learning process, guidance scheme can enable students successfully avoid learning order chaos, unclear objectives and tasks, unclear selection and so on. Therefore, teachers should carefully plan and design guidance scheme in the student participation, optimize the guidance scheme, to ensure smooth progress of learning activities.

Design Guidance Cooperation Construction. The cooperation construction stage should have the appropriate construction goal. For the cognitive construction subject, teachers should let students clear achieving what goals through the construction of cooperation, to understand, master, applicator and develop knowledge, knowledge framework, cognitive skills and problems solving strategies. For the skills construction subject, teachers should make students clear through cooperative construction, on the basis of understanding skill standardization, how to carry out skills innovation. For the feeling construction theme, teachers should let students clear through cooperation construction, on the basis of acceptance, response, evaluation and organization, obtain how emotion experience, how to become a part of the value of their own character. The stage of cooperative construction requires teachers to choose the content of design and construction. These contents not only come from the basic concepts, principles and methods, have the corresponding carrying capacity of the subject content, but also should be real and open content. In the cooperative construction stage, the students should be grouped according to the target content. Each group share different thematic tasks, cooperative construction, exchange ideas, and share results [8].

Optimization Education Technique. Compared with the traditional technical means, the function and the value of the new technology are different. Teachers should integrate new technology means 
(such as video production, supporting platform, etc.) and traditional techniques (such as chalk, blackboard, language, etc.), so do complementary advantages and combinatorial optimization.

Stimulate Students' Learning Motivation. Because of the application of new technology, the flipped classroom is free from the constraint of "chalk + blackboard", which has changed the way of learning. Therefore, students need to have a stronger motivation and internal drive. At this time, teachers need to stimulate the learning motivation of the learners in the self-questioning stage and the cooperative construction stage to improve the inner drive of the active learning of students.

\section{The Practice of Flipped Classroom Teaching Based on the Network Platform}

Developing the flipped classroom teaching practice, should carry out learning design before class, design of classroom teaching activities, network teaching platform utilization, construction of network teaching resources, student achievement evaluation system and so on. Combining with the course "Application of Excel in Business", the flipped classroom teaching practice was carried out.

Learning Design before Class. Learning design before class includes learning objectives, learning content, learning thinking path and learning summary. Learning objectives design includes the outcome and experience goals design. The outcome goal is to design what the students want to master the knowledge and ability. Experience goals include that students has gained experiences, which links are easy to grasp, which links or knowledge point is difficult to understand and master, etc.. Before class learning content is according to the requirements of the syllabus, decompose curriculum knowledge, a part of the knowledge points can be made micro video and upload it on the network platform for students learning to use, while the students to expand knowledge learning based on network teaching platform and the relevant professional website. Learning thinking path is to provide students with a certain learning reference path, such as according to the micro lesson video, MOOC and other online courses to learn, etc. Learning summary is to summarize the problems, network course resources and learning effects in the learning process [9]. According to the characteristics of different courses, it is best to take the form of enterprise practical cases to study learning design before class. "Application of Excel in Business" course has designed teaching cases according to the actual business process of the enterprise, such as the application of Excel in the production management, in the sales management, in human resources management and in the financial management. According to the actual situation of students, teach the relevant cases through the micro video, so that students learn in advance and make a summary of the study.

Design of Classroom Teaching Activities. The design of classroom teaching activities mainly include class discussion, knowledge expansion, teaching difficult points, the future study direction and so on. The design of class discussion is to carry out discussion between students and teacher for solving students' problems in the learning before class. Student learning content before class, generally only learn individual knowledge point or single method. How effective cohesion between knowledge, solve the problem using a variety of ideas and methods, teacher should further explain to students in the class for expanding students' knowledge. Such as the course of "Application of Excel in Business", its first class involved formula content, those relative address reference, absolute address reference and mixed address reference content need to be expanded. For the teaching difficulties, teachers should focus on analysis and discussion. Such as the course of "Application of Excel in Business", formula address reference is a difficult, teacher should focus on the problems of formula address changing in the formula copy process. For students' future study direction, based on the existing knowledge of the students, put forward the study content and learning methods in the next step, to provide students with reference learning path.

Network Teaching Platform Utilization. It is a more effective mean to use the network platform to carry out flipped classroom teaching. At present, the common network teaching platforms in Chinese Universities have foreign commercial platform, such as Blackboard, open source software Moodle, and so on, the domestic commercial platform, such as the Shanghai Excellence Center.

With Tencent QQ chat software function continuously enhanced, its application in teaching has gradually carried out, so QQ software as a network teaching tool, attracts more and more teachers and students get more extensive application. QQ integrated a variety of network communication mode 
and provides the powerful interactive tools, included communication tools (such as email, group chat and private chat tools, video chat tools, forums, etc.), collaboration tools (such as role-playing tools, virtual whiteboard, file sharing and file transfer tools, etc.), tracking assessment tools (such as the $\log$ comment function) and individual homepage space. Most university students has been using QQ to chat from the high school to now, have a good software base. Using QQ software to carry out the teaching is easy to operate, easy to understand, maintenance free and zero cost and other features, QQ is a very useful and efficient tool for Internet network teaching. This study used QQ software tools to carry out the following network teaching.

Establish QQ Teaching Group. To establish curriculum QQ teaching group, such as Excel_teaching. Each student joined course QQ teaching group in his student number and name as a group mark name, to carry out communication and network learning assessment.

Network Teaching Resources Construction. Upload teaching outline, examination scheme, PPT documents and experimental guidance to the teaching curriculum QQ group sharing space, to facilitate students downloaded at any time, learning, understanding curriculum learning objectives, initiative to learn the relevant content. To the difficult understanding course knowledge, the micro video construction was carried out. Such as the mail merge, combination chart, dynamic chart, program management, simulation operation, exponential smoothing, regression analysis and other content in the "Application of Excel in Business" course, were constructed to the micro teaching video to be uploaded to the QQ group shared space.

Network Teaching Discussion. Using teaching of QQ group to discuss the previous lesson content and homework, and put forward the main contents of the next class discussion questions, let students to study them through the textbooks, CNKI and related websites, forming their own point of view, in the next classroom to carry out further discussion, to clear the problem solving direction, thinking path and reference scheme. To enhance studying the latest computer technology and discuss students' future innovation, entrepreneurship, and combined with the professional learning research, let students understand the application of computer technology in all aspects of society and the positive significance of their future innovation, entrepreneurship and professional learning.

Learning Evaluation Scheme. Building a scientific and effective learning evaluation program will bring a huge boost to the learning of students. Learning evaluation scheme not only to assessment of students' learning of the basic content of the curriculum, but also to promote cultivating of students' independent thinking, autonomous learning behavior and habits, influence the students' humanistic spirit, and cultivate students' innovative thinking and ability of application [10]. The design of the learning evaluation program included the process evaluation and summary evaluation.

Process Evaluation Program. The usual academic performance has been designed for the course total score of $50 \%$, of which $10 \%$ of classroom discussion, homework $30 \%$ and network learning $10 \%$. Classroom discussion evaluation can be carried out from the aspects of students to ask questions, answer questions and participate in the discussion. Homework assessment focuses on training students' independently think and comprehensive solving problems ability. First of all, to design the homework that there is no unified standard answer. Secondly, pay attention to the students' ability of solving practical problems, and homework closely with the actual situation of enterprises. In the course of "Application of Excel in Business", designed teaching cases of enterprise production, sales, financial management and human resources management. Through the completion of each homework, students not only learn the knowledge of Excel data analysis, but also understand the business process and the actual operation data processing, so as to improve the students' comprehensive analysis and solving problem ability. Network learning assessment can be carried out from the number of student login network teaching platform, the number of network learning discussion and providing solutions.

Summary Evaluation. Summary evaluation score was the $50 \%$ of the course total score, and summary evaluation test was carried out by the computer examination system. Summary evaluation not only assessed the students' learning basic content, but also to promote the improvement of students' comprehensive learning ability. Exam questions not only selected the knowledge content of computer theory and technology, designed some titles of famous scientists' and entrepreneurs' dedication of promoting computer technology of the invention and development, also designed some 
items of solving the practical problems of enterprises. To guide students to read the teaching materials, related websites and magazines, promote students to take the initiative, absorb knowledge, enhance the comprehensive ability, strengthen the cultivation of students' innovative thinking.

\section{Conclusions}

Flipped classroom changed the role of teachers and students. Outside class, the students learn by themselves, and become the master of the study. In the class, the teacher answers students' questions, become the students' mentor.

Flipped classroom improved the teaching efficiency of the course. "Application of Excel in Business" course teaching plan was 48 hours, using flipped classroom teaching, 36 hours on the completion of the task, saving $25 \%$ of the time.

Flipped classroom improved the teaching effects. Many students not only effectively learned the relevant knowledge and enhanced the ability of solving problems, but also in the classroom, came to the podium to explain the problem solution, greatly enhanced the quality of teaching.

\section{Acknowledgement}

This study was supported by 2014 annual innovative research project in Department of Education of Guangdong Province (No.2014GXJK109), 2014 annual liberal arts university computer teaching reform project in University Liberal Arts Computer Basic Teaching Guiding Committee of Ministry of Education of the People's Republic of China (No. 2014-B007).

\section{Literature References}

[1] Alan November, Brian Mull. Flipped Learning: A Response to Five Common Criticisms. http $/ /$ www.eschoolnews.com/2012/03/26/flipped-learning-a-response-to-five-common-critic is ms.

[2] Cynthia J. Brame. Flipping the Classroom. https://cft.vanderbilt.edu/guides-sub-pages/flippingthe-classroom/

[3] Salman Khan. Using Video to Reconstruct Education. http//v.163.com/movie/2011/7/C/6/M77ESEJF8_M77ESRDC6.html.

[4] The flipped classroom. http://www.kokuamai.com/test/flipped/

[5] Huijuan Li, Yanwei Yang, Hequn Liu. Research on Flipped Classroom Teaching Mode Based on Innovative Education. Education and Vocation, 2015.2:160-161.

[6] Guorong Zhang. Practice of Flipped Classroom Teaching Mode Based on Deep Learning. Higher Education Exploration, 2016.3: 87-92.

[7] Xiaofeng Yang. The Value Pursuit and Implementation Strategy of Flipped Classroom Teaching Mode. Education Review, 2016.3:20-24.

[8] Yunhui Li, Jun Wang. Design of the Learning Model in the Flipping Classroom System under the College Education Informatization Trend. Heilongjiang Researches on Higher Education, 2015.4: 166-169.

[9] Huanhuan Cai, Zhuozhang Duan. Task Analysis of Pre Class Teachers in the Flipped Classroom. Journal of Teaching and Management, 2016.2:77-79.

[10] Chengyan Li, Jun Gao, Yuanxin Tang, Deyun Chen. Research on the Teaching Evaluation System of Flipped Classroom. Computer Education, 2015.6: 101-103. 